every other question it has its extremes and a happy mean. There can be no question that the pendulum is swinging away from the indiscriminate use of alcohol as practiced in former days. This is true in our own profession, as evidenced by the fact that a large number of our best men are earnest members of the American Medical Temperance Association, which stands for a restricted use of alcohol in disease. In my judgment, we ought to deal with alcohol as we would with morphia, recog. nizing that it is an agent both for good and evil. I have long accepted as a maxim the terse statement of A ustin Flint, Jr., that "whenever a sufficient quantity of food, to meet all the needs of nutrition, can be taken and digested, alcohol is not only unnecessary but injurious." This statement applies both in health and disease. I think it is taking up an extreme posi tion to say that alcohol never has a legitinate use either in health or disease, and in this respect the author's views fail to meet my own. In moderate quantities it is surely oxidized, and if oxidized, it must be a producer to some degree of animal heat and force. In disease, where a "sufficient quantity of food can not always be ingested and digested," the importance of the use of alcohol is apparent, as a temporary prop to the vitality of the patient. It is only in these temporary con ditions that we find its highest value in disease. As an article of diet in health it is certainly unnecessary, if not immediately and tangibly injurious.

Dr. H. R. Slack, Lagrange, Ga.-I regret exceedingly that the author of this paper is not present, for I would like to inquire whence the quotation of Dr. Martin was obtained. It was my good fortune to have studied under Professor Martin at the Johns Hopkins University, and he taught: "According to circumstances alcohol may be either a poison or useful; when useful it may be regarded either as a force-generator or a force-regulator. It is sometimes a valuable medicine, but does no good in a healthy body. Its proper use is as a whip, to stimulate the flagging energies, and it enables the physician to win many a race for life that otherwise might be lost.". Dr. Osler recommends its use strongly in typhoid fever, and in pneumonia says: "It is the only remedy in many instances capable of tiding the patient over the dangerous period." There is no substance in the whole range of medicine concern ing the uses and effects of which there is a greater diversity of opinion than alcohol, some as the writer, holding that these are wholly bad and that "no good thing can come out of Nazareth" while to others it is an ideal stimulant, tonic and food. I hold an intermediate position, one that I consider the golden mean, and the position of Dr. Martin as stated before. I have seen many cases where its beneficial effects were marked. It is a well.known fact that the mortality from typhoid fever in the London Temperance Hospital has for the last twenty years been 15 to 16 per cent.; much greater than in other hospitals where alcohol is used. I believe that at present we have no medicine in the pharmacopeia that can replace alcohol as a stimulant, and in some cases its use is necessary.

\section{DIETETIC CAUSES OF INEBRIETY.}

Presented to the Section on Physiology and Dietetics, at the Forty-ninth Annual Meeting of the American Medical Association, held at Denver, Colo., June 7-10, 1898.

BY T. D. CROTHERS, M.D.

SUPERINTENDENT WALNUT LODGE HOSPITAL. HARTFORD, CONN.

Inebriety is one of the most complex neuroses and obscure border-land diseases known. To the average practitioner the inebriate is simply a weak, wilful, vicious man, who has full power to do different but th will not exercise it. When the inebriate is examined carefully, and all the facts of his inheritance and of his nutritional, and also mental life and growth are grouped, a uniform progressive line of disease is found. The pathologic conditions which precede alcohol and the conditions which follow from the use of alcohol, are marked in different degrees. The former are not recognized and the latter only recently have come into prominence. The use of alcohol is followed by conditions which differ very widely, and are unexplainable except by a study of preceding conditions before spirits was used. One of these conditions is heredity, that is the transmission of defects and predispositions to degenerate in certain directions, with or without special exciting causes. Another is nutrition, a third is disease and traumatism and its sequelæ, a fourth is culture and environment, and so on through a long list of causes. In all cases, it may be said that the nerve centers suffer from practical starvation, and the nurcotism from alcohol is grateful in covering up the irritation and pain demands for help. In my studies the nutrition of childhood has been found to be an active cause in many cases. I have divided these into the overfed and underfed cases. In the former the clinical history would follow these general outlines: The nursing child would be surfeited both at the breast and by infant foods. The central thought of the parents would be the danger of starvation and the need of constant ingestion of food. When indigestion followed, another nurse and changed foods in equal quantities would be given Later, when the child was able to occupy a pluce at the table with his parents, all discrimination was left to his own tastes, the parents reasoning that the appetite was the best guide and the child's food inclinations should be followed. Anything the child called for as foods or fluids were given freely. The disturbances of digestion which follow are usually treated as weaknesses and tendency to diseases. Consumption, rheumatism, disease of the liver, stomach and kidneys, and other formidable diseases are discerned in the horizon by the worldly-wise physician. Patent foods, climate cures, changes of school and culture and many remedies are tried. Finally puberty is passed, and the digestion is permanently impaired. The appetite is lawless and without control. The body is ill-nourished. Already fatty deposits have begun. The demand for foods and fluids are mere impulses. The taste is disordered. Large quantities of certain classes of foods are tuken, then abandoned. The same of fluids, teas, coffees, mineral waters, beers, wines and anything used at the table.

Indigestion and obscure or well.defined nerve failures, nerve disturbances, irregularities of sleep all follow. Then finally comes the subtle tonic bitters containing from 20 to 40 per cent. of alcohol, or the wines or whisky, and inebriety has come. The relief which spirits brings is so marked that it is continued, and then follows a rapid, sharp degeneration. and the inebriety is chronic and complex mental and physical changes appear; opium and other narcotics follow, changing from one to another. This picture is not confined to children of wealthy persons, but occurs in all the various circles of society, in the families with moderate means, and occurs among children who are obliged to begin the serious work of life at an early age. The dietetic delusions of parents are engrafted and graven in the minds of children and the end is inebriety. Some of these cases take on paroxysmal forms, after spirits are used. Thus, an attack of acute indigestion is followed by a drink craze which after a certain time subsides, and breaks out again after a free interval. They become periodic drinkers, and when they die show in the postmortem remarkable stomach degenerations. It is found that the sudden, unreasoning outbreaks of what is called alcoholism, or the use of spirits to prolonged intoxication, occur in those delusional dyspeptics who, from infancy, have had no dietetic or food control. Such morbid eaters occur often among prominent men, and when they begin to use spirits they have no power of control and are soon pronounced inebriates. In these cases digestion is early strained and stimulated far beyond the needs of the body, and the food, non- 
assimilable or in excess of the demands of the organ. ism, accumulates and becomes sources of degeneration. Overgrowths, retarded growths, defective growths, with functional derangements both of physiologic and psycholoric control follow. Excessive nutrition in childhood is a cause of inebriety in later life, both with and without special exposure, and often among persons who by environment would uaturally not use spirits.

The second class of cases I have called the under. fed. By that I mean persons who have been practically starved in many ways the first twenty years of their lives. The starvation has come from exclusive diets used from necessity or from theory, or from carelessness and neglect. In very poor families the food from infancy would be potatoes, corn meal or pork almost exclusively, or fruits in more tropic climates, in some form of liquid foods, no variety and one article almost exclusively. In other families, from theory, children would be forced to use one class of food and no others, as for instance meats, or grains, or fruits, to the exclusion of every other class of foods. In the larger proportion of cases, carelessness prevails. Children are supposed after the nursing period to eat the same foods as the rest of the family, and are given without discrimination anything which is prepared. No care is taken of their diet, no judgment is exercised as to quality, variety or niature of foods. At one time fruit is used to excess, or vegetables, or meats, or grains, according to the supply. In the family of a country grocer three boys, after a protracted period of indigestion, became inebriates. I found that the diet of the family was largely depend. ent on the surplus of perishable food which accumulated in the store. At one time it was eggs, then fruits, then grains, then meats. This diet was insufficient, and states of starvation and defective growth followed which led most naturally to the narcotic of alcohol. In another case two sons of a clergyman began to use alcohol to excess without any apparent reason. The theory of the parents that excess of quantity and variety of food was dangerous, had been carried out from infancy. A limited and always insufficient quantity of potatoes and bread had constituted the daily food. When these children grew up they ate to great excess away from home. This, with starvation at home, broke up the normal nutrition, and the relief from alcohol was so great as to be irresistible. In a case of unusual mental ability where the user of spirits was of an exceptional character, and the effort to recover was of equal intensity to the craze for drink, it was found that regular, uniform diet of moderate variety of foods was medicinal. As long as his diet was mathematically uniform and unchangeable he could keep from spirits, but the slightest deviation in time of using food and their quantity and quality would destroy his mental control. It was ascertained that his mother, during pregnancy and lactation, entertained some opinions of foods and their value and put them in practice in her own case. The result was a very sensitive nutrient organization in the child, with anemic sick headache throughout childhood, great excesses at puberty in foods and drinks and continued nutritive disturbances up to manhood. Then a period of drug-taking and periodic inebriety. Now he is able to be a total abstainer only by the most careful attention to diet. There appears to be a close relation between the excessive use of meat in childhood and inebriety in early middle life.
While the facts are not sufficient from which to draw any general positive conclusions, there are many reasons for supposing that often they are as cause and effect. This appears clear in this case: The parents in a family entertained very strong confidence in the value of meat as an ideal food. It was used and urged upon the children in all forms. One boy began to drink in college and died after a short period of great excess. A sister was hysteric and became a drug-taker, and died early. Later the parents abandoned meat for grains and fruits, and three children brought up on this diet have continued well and healthy. The conditions and surroundings are the same, but the vigor of the children varied widely. Beef-eating foreigners who bring up children on this diet are astonished that their children turn to beer and wine so early. The reason is the early and deranged digestion which, calling for relief of some kind, finds it in alcohol. This question of the value or injury from meats and grains is yet to be studied and settled. After alcohol is taken to excess, the complications of nutrition are many and serious. One of the first essentials in treatment is the elimination of toxins and proper nutrition.

Foods of easy digestion with moderate variety and quantity, and taken at regular intervals are required. Concentrated foods may be useful in some cases and injurious in others. Frequent use of food and in large quantities is to be avoided.

Two conditions exist, impaired and defective nutrition and congestion from over-accumulation of toxins and waste unassimilable foods and starvation. The treatment is not by routine or specifics, either foods or drugs, but by the use of many and complex measures to meet the special conditions called for. Inebriety is not confined nor traceable to any special cause, and its treatment can not be successful by any one measure or form of drug. The unexpected outbreak of the drink craze in early life and the persistence of the use of spirits is unmistakable evidence of some central defect of nerve centers and neurons. These defects are most likely to come from nutrient degenerations in what way no one can tell, yet the facts point out a distinct relation.

The drug poisoning from alcohol, opium and other narcotics most clearly affects the nutrition, and in all cases is followed by veritable starvation and failure to assimilate the food required. Where causes are traceable to early life the degeneration is greater and the symptoms more complex. The same nutritive prob. lems appear in all cases. The use of tea, coffee and wines at meals in early life is a starting point for both degeneration and inebriety later. Many of the most intractable cases of pronounced degeneration where the alcoholic symptom was maniacal have a history of early tea and coffee drinking. The facts fully sustain the assertion, that a large number of cases of inebriety are traceable to defective nutrition in early life. This may be both starvation and poisoning, and the extreme persistence of these states is remarkable. Thus the bad living of childhood with its defects of nutrition may appear in later life as in the following: A child of healthy parents who were killed by accident, was kept six years in the family of a German and wine drinker. $\mathrm{He}$ was over-fed and given wine freely at the table, and was considered sickly. Then he was taken by another family and brought up very carefully and abstemiously. After a long temperate life he retired from business at sixty, and soon after began 
to over-eat and drink wine at meals, and finally be. came an inebriate. Many cases are traceable where inebriety began at or before puberty, or after then subsided and later in life broke out again without any special causes. The expression "sowing wild oats" often describes a period of excessive use of spirits and nutritional disturbances, and then a full subsidence and a long period of temperate living. Far down in middle and later life a recurrence of this excess period appears again and often death follows. Here there is a persistence of nutrient and poison effects, which breaks out like some masked tire which has been dormant for a long time. The appearance of inebriety is usually sudden and without any exciting causes, and the change in conduct and manner of living is unexplainable. The same methods of using spirits and the same food impulses and tastes, and same surroundings as far as possible, appearing after a lapse of a lifetime, show that early defects are not affected by time. I conclude at this point with a summary of what I have intended to make clear in this study:

1. Inebriety is a most complex neurosis. The causes are equally complex, and include all the various states of degeneration which influence and disturb nutrition.

2. Obscure indigestion begins, and for this drugs and bitters containing alcohol are used. The narcotism which follows is so grateful that it is continued.

3. Dietetic delusions are fostered in the minds of parents and children, and from this many different forms of inebriety begin.

4. Often the most maniacal and chronic inebriates are from these delusional dyspeptics.

5. Starvation is present in many of these cases. The quality and variety of foods are deficient and defective nourishment follows.

6 . The uniformity of taking foods and the quality and variety are essential. This and nutritional rest and mental anxiety are important factors.

7. The inebriety following these conditions is successfully treated by elimination of the toxins and special correction of the nutrition.

8. Nutrition is a very active cause in the production of inebriety, and should receive a careful study in all cases.

DISCUSSION,

D. R. Brower, Chicago-I am pleased to have heard the admirable paper of my distinguished friend, Dr. Crothers. No man can speak with more authority than he can on the etiology and treatment of inebriety ; and what he says is as sensible as it is learned.

It is very gratifying to see so much interest being manifested by the profession on the subject of dietetics, for there is no more powerful agent in the causation and cure of disease. The recognition of the fact that imperfect digestion leads to auto-intoxication, and this to development of diseases of the nervous system, and the further fact that inadequate or im properly cooked food will produce the same result have been of much benefit to all concerned.

The publication far and wide of further facts that tea and coffee in childhood will develop a taste for stimulants that later along will produce inebriety, will save many from this dreadful state. The use of tobacco by the young may also be an important factor in this same pathogenesis.

Dr. Crothers (in closing)-The special object of my paper was to call attention to the injuries which always follow the use of alcohol in children. A very large amount of experimental evidence from the laboratory, in the use of alcohol on animals has been gathered for other purposes, which makes the facts conclusive. The disability and defects of children in all circles of life who have used spirits freely in childhood are to be seen in every town and country, I am pleased to most heartily agree with the speaker who preceded $m \theta$, in the statement of the skill in promoting the growth of animals, in fattening them, in developing their best qualities, so highly developed among stockmen and farmers, while the develop- ment of children physically through food channels, is totally neglected. We are on the frontiers of a new field of much important work, prominent of which is to clear away the deluslons which infest our conceptions of child growth and dietetics. One of these delusions is the food value of spirits and its harm. eseness. in early life. Our foreign population have strong views of alcohol or beer in childhood. Many others cling to the idea of stimulation and increase of vigor from spirits. These delusions must be overcome and a clearer conception of dietetics as a whole must follow, then we shall do with children what farmers do now with animals.

\section{TUBERCULOSIS: ITS HYGIENE AND DIETETICS.}

Presented to the Section on Physiology and Dietetics at the Forty-ninth Annual Meeting of the American Medical Association, held at Denver, Colo., June 7-10, 1898.

BY A. T. CUZNER, M.D.

GILMORE, FLA.

Tuberculosis in some form or other may fairly be considered the almost universal disease of man. "Schlenker made 100 consecutive postmortems on adults and children. He carefully examined every part of their bodies and found 65 per cent. tuberculous. In over 4000 successive postmortems made in Breslau in 1893, one-third of the bodies contained gross tuberculous lesions. If the microscope had been used, probably enough lesions could have been discovered to make 2500 infections. Babes fourd lesions of the bronchial glands in more than one-half of his postmortems on children. Biggs could demonstrate characteristic lesions in the lunge alone in 60 per cent. of his postmortems. Grawitz found primary tuberculous deposits in the lungs in 152 out of 221 cases, being nearly 70 per cent. of all infections. Loomis found the bronchial glands infective to rabbits in eight out of thirty bodies apparently free from tuberculosis during life."

Upon examination of the death records of thirteen prisons located in different parts of the country, we find the deaths from tuberculosis to be 59.9 per cent. Doubtless tuberculous deposits could be found in the 40.1 per cent. remaining.

In an article in a September issue of the Illustrated American, Prof. Fletcher W. Hewes publishes a dial illustrating the ratio of deaths in the United States from the most prevalent diseases. This is a reproduction of the dial.

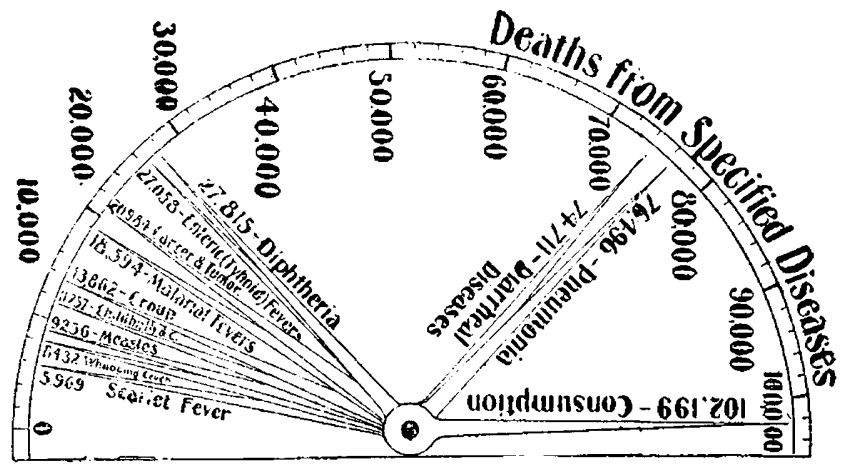

In proceeding with our investigation of this disease, it will be as well to consider as briefly as we can: 1 , the cellular pathology of the human tissues, and then in addition, what is known of the pathogenic germs thought by many to be the main cause of the disease: 2, the nature of tubercle, from which the disease takes its name; and 3 , the hygiene and dietetics of this complaint. 